\title{
Variation in tissue $\mathrm{Na}^{+}$content and the activity of SOS1 genes among two species and two related genera of Chrysanthemum

\author{
Jiaojiao Gao, Jing Sun, Peipei Cao, Liping Ren, Chen Liu, Sumei Chen, Fadi Chen and Jiafu Jiang*
}

\begin{abstract}
Background: Chrysanthemum, a leading ornamental species, does not tolerate salinity stress, although some of its related species do. The current level of understanding regarding the mechanisms underlying salinity tolerance in this botanical group is still limited.

Results: A comparison of the physiological responses to salinity stress was made between Chrysanthemum morifolium 'Jinba' and its more tolerant relatives Crossostephium chinense, Artemisia japonica and Chrysanthemum crassum. The stress induced a higher accumulation of $\mathrm{Na}^{+}$and more reduction of $\mathrm{K}^{+}$in C. morifolium than in $\mathrm{C}$. chinense, C. crassum and A. japonica, which also showed higher $\mathrm{K}^{+} / \mathrm{Na}^{+}$ratio. Homologs of an $\mathrm{Na}^{+} / \mathrm{H}^{+}$antiporter (SOS1) were isolated from each species. The gene carried by the tolerant plants were more strongly induced by salt stress than those carried by the non-tolerant ones. When expressed heterologously, they also conferred a greater degree of tolerance to a yeast mutant lacking $\mathrm{Na}^{+}$-pumping ATPase and plasma membrane $\mathrm{Na}^{+} / \mathrm{H}^{+}$antiporter activity. The data suggested that the products of AjSOS1, CrCSOS1 and CCSOS1 functioned more effectively as $\mathrm{Na}^{+}$ excluders than those of CMSOS1. Over expression of four SOS1s improves the salinity tolerance of transgenic plants and the overexpressing plants of SOS1s from salt tolerant plants were more tolerant than that from salt sensitive plants. In addition, the importance of certain AjSOS1 residues for effective ion transport activity and salinity tolerance was established by site-directed mutagenesis and heterologous expression in yeast.
\end{abstract}

Conclusions: AjSOS1, CrCSOS1 and CCSOS1 have potential as transgenes for enhancing salinity tolerance. Some of the mutations identified here may offer opportunities to better understand the mechanistic basis of salinity tolerance in the chrysanthemum complex.

Keywords: Chrysanthemum morifolium, Compositae, SOS1, Functional characterization, Complementation assay

\section{Background}

Soil salinity is becoming a severe environmental stress all over the world. Currently, over 800 million hectares of the world's arable land are adversely affected by salinity [1]. The major toxic cation present in saline soils is $\mathrm{Na}^{+}$, so under saline conditions, plants must minimize their cytosolic $\mathrm{Na}^{+}$concentration to withstand the stress [2]. Three strategies have evolved to avoid the build-up of $\mathrm{Na}^{+}$in the plant shoot: the first restricts the movement of the ion from the soil into the root, the second sequesters $\mathrm{Na}^{+}$in the vacuole, and the third actively pumps $\mathrm{Na}^{+}$out of the

\footnotetext{
* Correspondence: jiangjiafu@njau.edu.cn

College of Horticulture, Nanjing Agricultural University, Nanjing 210095, China
}

cytoplasm into the soil [1, 3-5]. Various ion transporters are involved in these processes, but a particularly prominent class is represented by the $\mathrm{Na}^{+} / \mathrm{H}^{+}$antiporters. So far, two types of $\mathrm{Na}^{+} / \mathrm{H}^{+}$antiporter NHE/NHX1 and NHA/ SOS1 have been well characterized $[2,6]$.

AtSOS1 is the first plasma membrane $\mathrm{Na}^{+} / \mathrm{H}^{+}$antiporter gene cloned from higher plant, primarily expression of AtSOS1 in epidermal cells at the root tip and in parenchyma at the xylem-symplast boundary of roots, stems and leaves, implying a role of this transporter in extruding $\mathrm{Na}^{+}$to the growth medium and controlling longdistance $\mathrm{Na}^{+}$transport in plants. Furthmore, under moderate salinity, sos 1 mutant accumulated less $\mathrm{Na}^{+}$in its shoots than WT (wild-type) plants, also indicating that SOS1 participates in loading of $\mathrm{Na}^{+}$into the xylem 
$[7,8]$. Recently, several similar studies indicated this critical function in tomato [9] and in Thellungiella salsuginea [10]. SOS1 might also be involved in $\mathrm{K}^{+}$nutrition in plants and under salt stress it is more vital for the plant to keep a high $\mathrm{K}^{+} / \mathrm{Na}^{+}$ratio [6]. The sos 1 mutant showed significantly reduced high affinity $\mathrm{K}^{+}$uptake and $\mathrm{K}^{+}$content $[11,12]$, while higher $\mathrm{K}^{+}$efflux from sos1 root than that in WT plants [13]. Qi and Spalding (2004) demonstrated that SOS1 was required for protecting $\mathrm{K}^{+}$uptake through AKT1 and compromised $\mathrm{K}^{+}$ nutrition during salt stress [14]. In addition, ZxSOS1 controls long distance transport and spatial distribution of $\mathrm{Na}^{+}$and $\mathrm{K}^{+}$and maintains $\mathrm{Na}^{+}, \mathrm{K}^{+}$homeostasis in the xerophyte Zygophyllum xanthoxylum [15]. Together, SOS1 is essential for plant to cope with salt stress by maintaining ions homeostasis and controlling longdistance $\mathrm{Na}^{+}$transport via the xylem $[16,17]$.

The recognition of AtSOS1 has facilitated the isolation of homologs from a growing number of plant species. Some of these have been tested by their heterologous expression in either yeast or bacterial hosts which lack their own $\mathrm{Na}^{+}$transport system $[9,18-26]$. Loss-offunction mutants of AtSOS1 is salinity hypersensitive [12], while constitutive expression of SOS1 in both A. thaliana itself as well as in other plant species, including chrysanthemum, improves the level of salinity tolerance [18, 20, 27-31].

The leading ornamental species chrysanthemum does not readily tolerate salinity stress, although some of its many related species do. The current level of understanding the mechanisms of salinity tolerance in this botanical group is still limited [32]. Here, the morphological effects of salinity stress, along with the extent of $\mathrm{Na}^{+}$and $\mathrm{K}^{+}$accumulation in chrysanthemum and its three more tolerant related species $(C$. chinense, $A$. japonica and $C$. crassum) have been explored. The SOS1 homologs present in each of the four species has been isolated and their contribution to salinity tolerance assessed by heterologously expressing them in a yeast mutant ANT3, and in transgenic chrysanthemum and $A$. thaliana. Furthermore, some important amino acid polymorphism for effective ion transport activity and salinity tolerance was also identified by mutagenesis.

\section{Results}

\section{Variation for salinity tolerance in the chrysanthemum complex}

Most of the leaves of $C$. morifolium plants became wilted and chlorotic following a ten day exposure to the salinity stress, and their lower leaves were largely necrotic $C$. crassum plants were less severely affected by the treatment, while there was no evidence of any damage to either $C$. chinense or $A$. japonica plants, the leaves of which stayed green, with the plants maintaining a near- normal level of growth for up to 14 days (Fig. 1). Under the non-stressed growing conditions, there was no variation in tissue $\mathrm{Na}^{+}$concent between the four test species. However, when the plants were exposed to salinity, the tissue $\mathrm{Na}^{+}$content throughout the plant was increased in all four species. The mean increase was notably lower for $C$. chinense and A. japonica: in these two species, the $\mathrm{Na}^{+}$content in the roots (compared to the levels in non-stressed plants) rose by only $142.0 \%$ and $156.0 \%$ respectively, while for C. crassum and C. morifolium plants, the increase was $300.0 \%$ and $324.0 \%$ (Fig. 2a). The leaves behaved similarly, with the $\mathrm{Na}^{+}$content rising more markedly in $C$. morifolium than in others. The $\mathrm{Na}^{+}$content in the leaves of C. morifolium was $125.0 \%, 169.0 \%$ and $189.0 \%$ that present in $C$. crassum, $C$. chinense and A. japonica plants exposed to the $\mathrm{NaCl}$ stress respectively (Fig. 2c). Moreover, the $\mathrm{Na}^{+}$ content in the stems behaved in a consistent way, it was highest in C. morifolium, moderate in C. crassum and low in both A. japonica and C. chinense (Fig. 2b).

$\mathrm{K}^{+}$concent in the roots of $C$. chinense, $A$. japonica and $C$. crassum plants show nearly unchanged between control and salt stress except that of $C$. morifolium plants, whose $\mathrm{K}^{+}$contents were significantly decreased (Fig. 2d). $\mathrm{K}^{+}$level in both $A$. japonica and $C$. chinense stems was also unchanged, on the contrary, $\mathrm{K}^{+}$content in the stems of C. crassum and C. morifolium was distinctly reduced by $23.2 \%$ and $43.6 \%$, respectively (Fig. 2e). While $\mathrm{K}^{+}$content in the leaves of all the plants tended to decrease, the reduction was far more significant in C. morifolium, i.e., 54.71 \% (Fig. 2f). Relative to normal condition, salinity appreciably decreased the $\mathrm{K}$ ${ }^{+} / \mathrm{Na}^{+}$ratio throughout the plants. C. chinense and $A$. japonica exhibited the highest $\mathrm{K}^{+} / \mathrm{Na}^{+}$ratio of 5.7 and 5.6, respectively. In comparison, $C$. morifolium showed a minimum value in this ratio (1.8), while $C$. crassum showed an intermediate ratio of 3.1 (Fig. 2g-i). Overall, $\mathrm{K}^{+} / \mathrm{Na}^{+}$ratio of the salt-sensitive plants was much lower than that of the salt-tolerant plants, indicating that salttolerant plants excluded $\mathrm{Na}^{+}$and imported $\mathrm{K}^{+}$more effectively than salt-sensitive plants did.

\section{Sequence analysis of the SOS1 homologs}

A summary description of the AjSOS1, CrCSOS1, CcSOS1 and CmSOS1 sequences is given in Additional file 1: Table S2. The ORF (open reading frames) sequence of the derived CCSOS1 fully matched that given in [23], but the UTR sequence differed slightly. All four SOS1 sequences were predicted to encode a $\mathrm{Na}^{+} / \mathrm{H}^{+}$antiporter. Both AjSOS1 and CrcSOS1 harbored a 1147aa ORF, whereas the CcSOS1 and CmSOS1 products were two residues shorter. The secondary structure of the four SOS1 proteins featured 12 transmembrane domains in their $\mathrm{N}$ terminal region according to TMPRED and included a long 


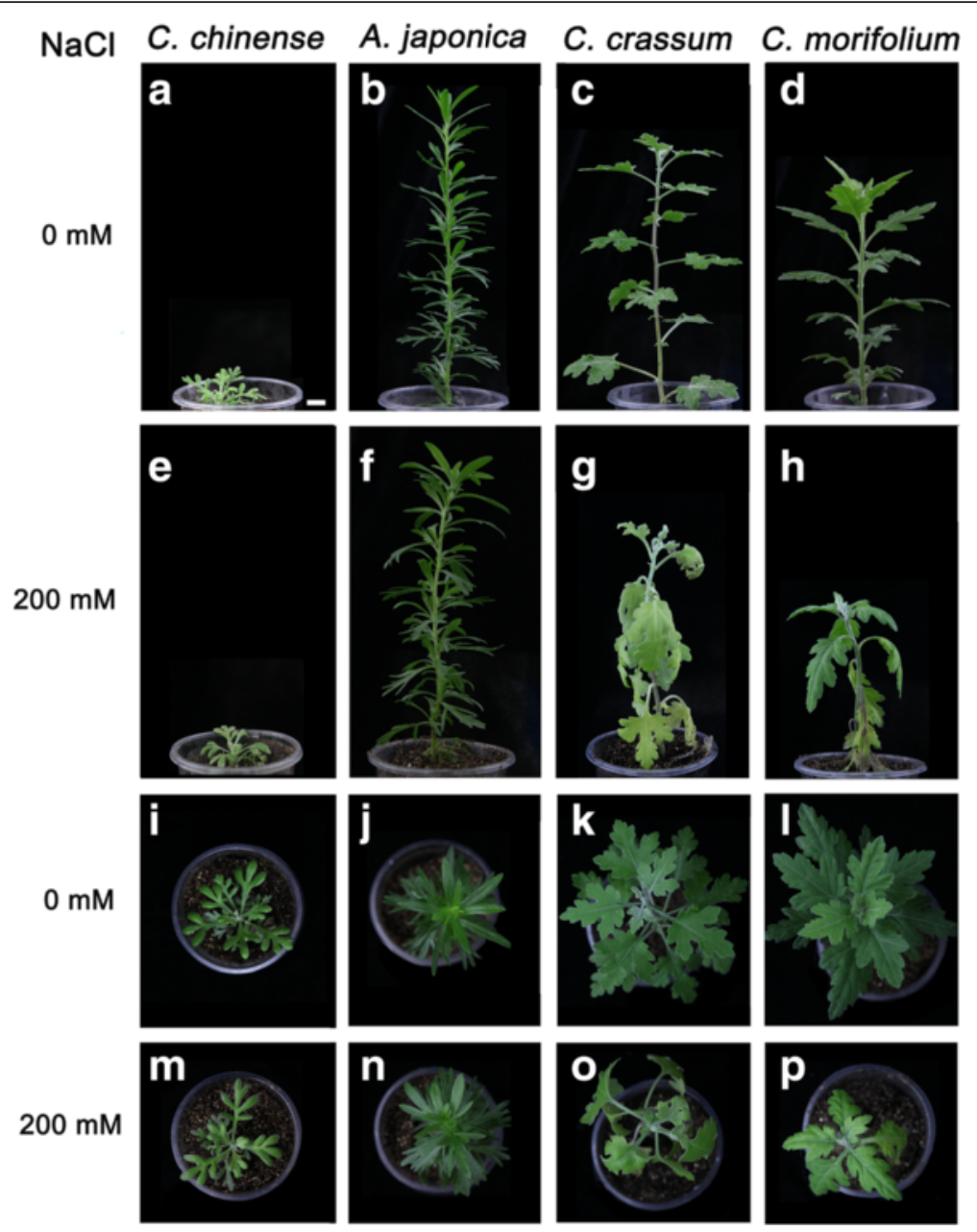

Fig. 1 The phenotypic response of chrysanthemum and its three close relatives to a ten day exposure to $200 \mathrm{mM} \mathrm{NaCl}$. a-h Side view; i-p Vertical view from above; $\mathbf{a}-\mathbf{d}$ and $\mathbf{i}-\mathbf{I}$ Plants grown in the absence of stress; $\mathbf{e}-\mathbf{h}$ and $\mathbf{m}$ - $\mathbf{p}$ plants exposed to $\mathrm{NaCl}$. $\mathbf{a}, \mathbf{e}, \mathbf{i}, \mathbf{m}$ C. chinense, $\mathbf{b}, \mathbf{f}, \mathbf{j}, \mathbf{n}$ A. japonica, c, $\mathbf{g}, \mathbf{k}, \mathbf{o}$ C. crassum, $\mathbf{d}, \mathbf{h}, \mathbf{I}, \mathbf{p}$ C. morifolium. Bar $=1.0 \mathrm{~cm}$

hydrophilic cytoplasmic tail in their $\mathrm{C}$ terminal segment (Fig. 3). The levels of peptide identity between AjSOS1 and the other three proteins were $98.5 \%$ (CrcSOS1), $97.0 \%(\mathrm{CcSOS} 1)$ and $97.4 \%$ (CmSOS1); those between CrcSOS1 and the other two proteins were $97.1 \%$ (CcSOS1) and $97.3 \%$ (CmSOS1); and that between CCSOS1 and CmSOS1 was $99.5 \%$. Comparisons with other plant SOS1s revealed a high degree of sequence conservation: for example the level of amino acid sequence identity between four cloned SOS1s and $A$. thaliana AtSOS1 was $90.3 \%$, with the tomato SISOS1 $91.8 \%$, with rice OsSOS1 $90.1 \%$ and with Helianthus tuberosus HtSOS1 $94.7 \%$. A phylogenetic analysis between four SOS1s and other palnt SOS1 transports $[7,9,15,18,19,21,24-27,29,33-46]$ showed that AjSOS1 and CrcSOS1 were closely relatives, as were CcSOS1 and CmSOS1, while the nearest relatives of the four SOS1s as a group were HtSOS1 and SISOS1 (Fig. 4). The presence of three conserved domains is required for the activity and regulation of the SOS1 protein: these are Nhap (an $\mathrm{Na}^{+} / \mathrm{H}^{+}$exchanger domain spanning the transmembrane region), InhiBD (an auto-inhibitory domain) and S2P (a phosphorylation motif recognized by SOS2) [19, 47], and all three were present in the four SOS1s analysed here (Fig. 3).

\section{SOS1 transcription profiling}

In the roots, the abundance of AjSOS1 transcript increased gradually of salinity stressed plants, reaching a level of 3.87 fold above the base level after a $24 \mathrm{~h}$ exposure to $200 \mathrm{mM} \mathrm{NaCl}$. CmSOS1 expression level increased only slowly over the first four hours of the treatment, peaking by $12 \mathrm{~h}$, then decreased slightly, while the transcripts of CrcSOS1 and CcSOS1 maintained relatively constant (Fig. 5a). In the stems, all four SOS1s were up-regulated by the stress, their transcripts were greatest after $12 \mathrm{~h}$ (Fig. 5b). In the leaves, the level of transcription of both 


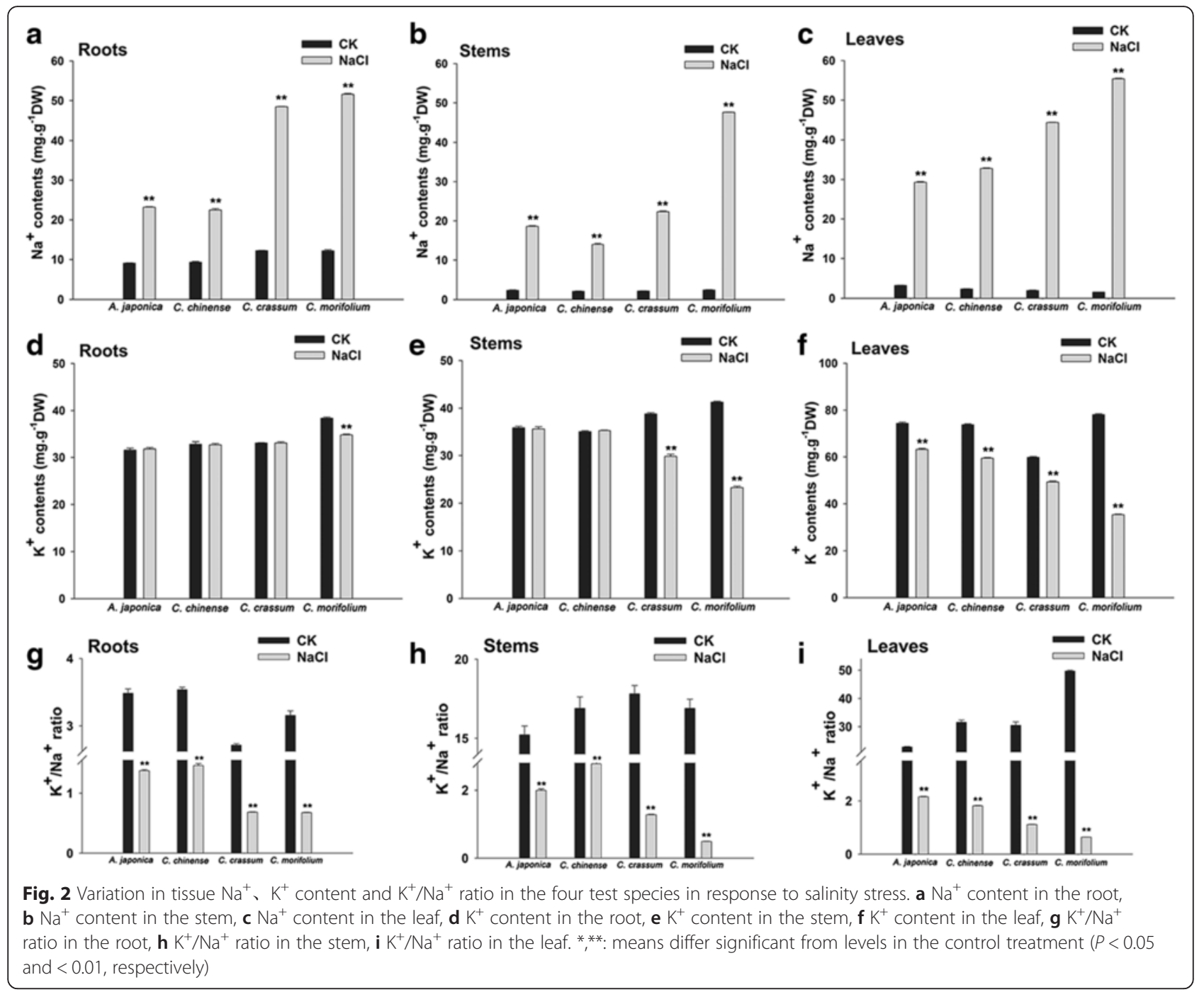

CrcSOS1 and CmSOS1 was highest at 24 $\mathrm{h}$; that of AjSOS1 rosed most sharply between $4 \mathrm{~h}$ and $12 \mathrm{~h}$, thereafter declined; and that of CCSOS1 remained relatively constant, with a two fold up-regulation occurring at $4 \mathrm{~h}$ (Fig. 5c). In essence, all four SOS1s were up-regulated by exposure to salinity, and the abundance of SOS1 transcript was greater in the more salinity tolerant plants.

\section{Complementation of the yeast mutant with four SOS1s}

All the yeast cells grew freely on YPDA in the absence of $\mathrm{NaCl}$ and one of the four related SOS1s transformed ANT3 cells grew much better on AP NaCl-containing medium than the control strain (Fig. 6a-d). A comparison of the ability of four SOS1s transformants to grow in the presence of salt especially at $70 \mathrm{mM} \mathrm{NaCl}$ showed that the inclusion of AjSOS1 was the most beneficial, followed by that of CrCSOS1; the strain carrying CcSOS1 was better than CmSOS1, but was worse than CrCSOS1, while the inclusion of CmSOS1 was the least salinity tolerant of the transformed cells (Fig. 6d). Furthermore, qPCR (quantitative real-time polymerase chain reaction) analysis of the SOS1 expression levels were almost the same between yeast transformants for four SOS1s (Fig. 6e). The data demonstrated that $\mathrm{Na}^{+} / \mathrm{H}^{+}$antiporter activity of four SOS1s was essential and AjSOS1, CrcSOS1 and CcSOS1 were fully able to exclude $\mathrm{Na}^{+}$ when expressed in yeast.

Overexpression of four SOS1s enhances salinity tolerance in transgenic chrysanthemum and Arabidopsis plants

Transgenic chrysanthemum lines overexpressing four SOS1s were successfully generated. $\mathrm{qPCR}$ analysis showed that compare with wide type (SM), SOS1 transcript abundance was not very high in the eight transgenic lines under control conditions but increased greatly upon $200 \mathrm{mM} \mathrm{NaCl}$ treatment (Fig. 7a). When exposure to saline hydroponics, most of the apex and edge of the lower leaves of all plants 


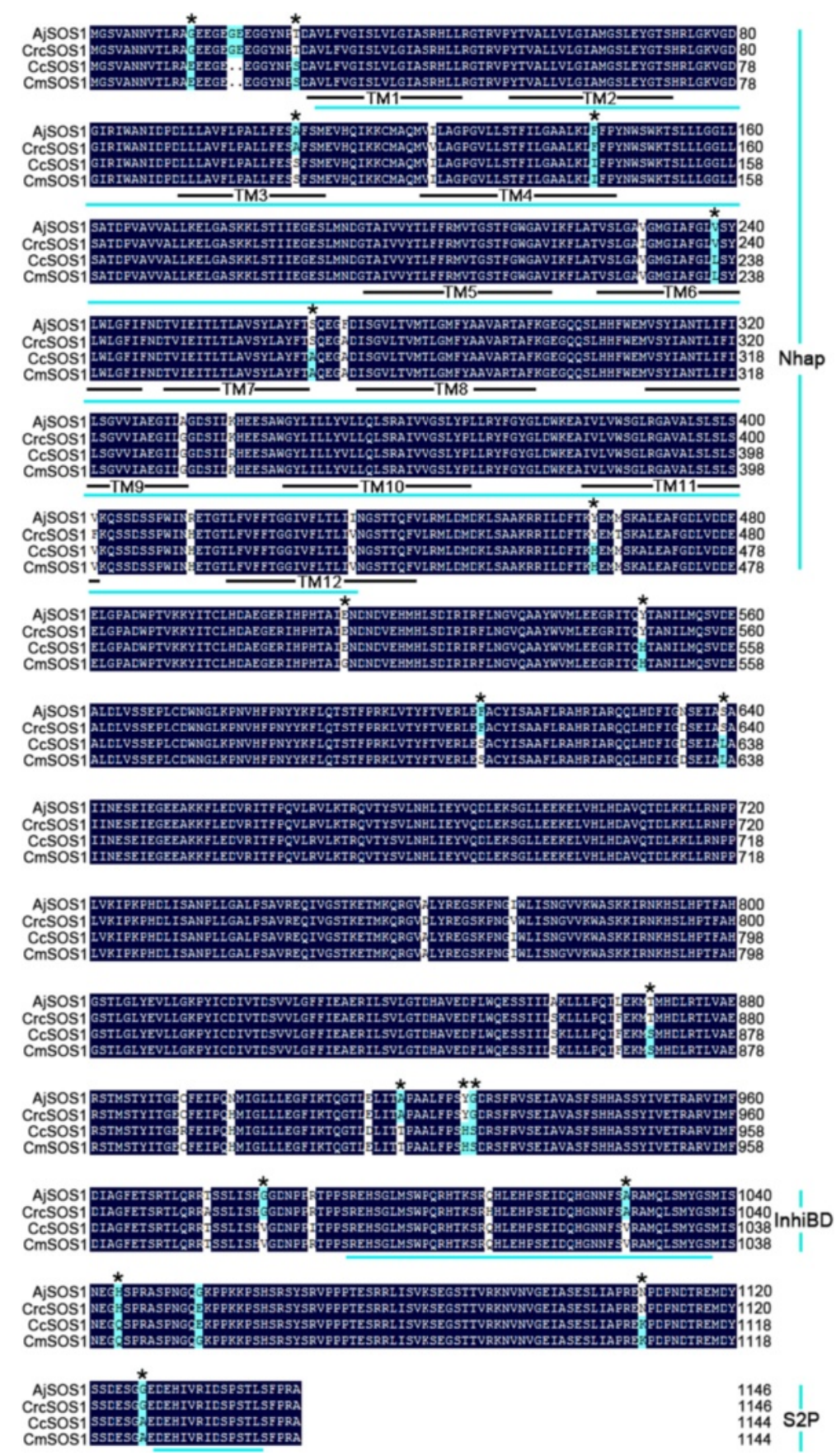

Fig. 3 Multiple amino acid sequence alignment between four SOS1s. The 12 putative transmembrane domains are underlined and numbered 1 through 12. Residues conserved in at least two proteins are highlighted in white and blue. The black asterisks indicate conserved residues which were replaced in the site-directed mutagenesis experiment (see Additional file 2: Figure S4). Nhap, an $\mathrm{Na}^{+} / \mathrm{H}^{+}$exchanger domain spanning the transmembrane region; InhiBD, an auto-inhibitory domain; S2P, SOS2 phosphorylation motif

showing signs of yellowing and necrotic after 1 day treatment, while after 3 days, the leaves of SM became severely necrotic and most plants died, the survival ratio of which was only $18 \%$. In the transgenic plants, symptoms of damage in leaves were much less evident in S1 and S2 than SM plants, but were worse than that of other transgenic plants, most of their upper leaves still remained green, and with less affected by salinity stress, which showed the transgenic plants maintained higher chlorophyll contents. The chlorophyll content is often used as index of salt tolerance in plants under salt stress, such as in Arabidopsis [48] and 


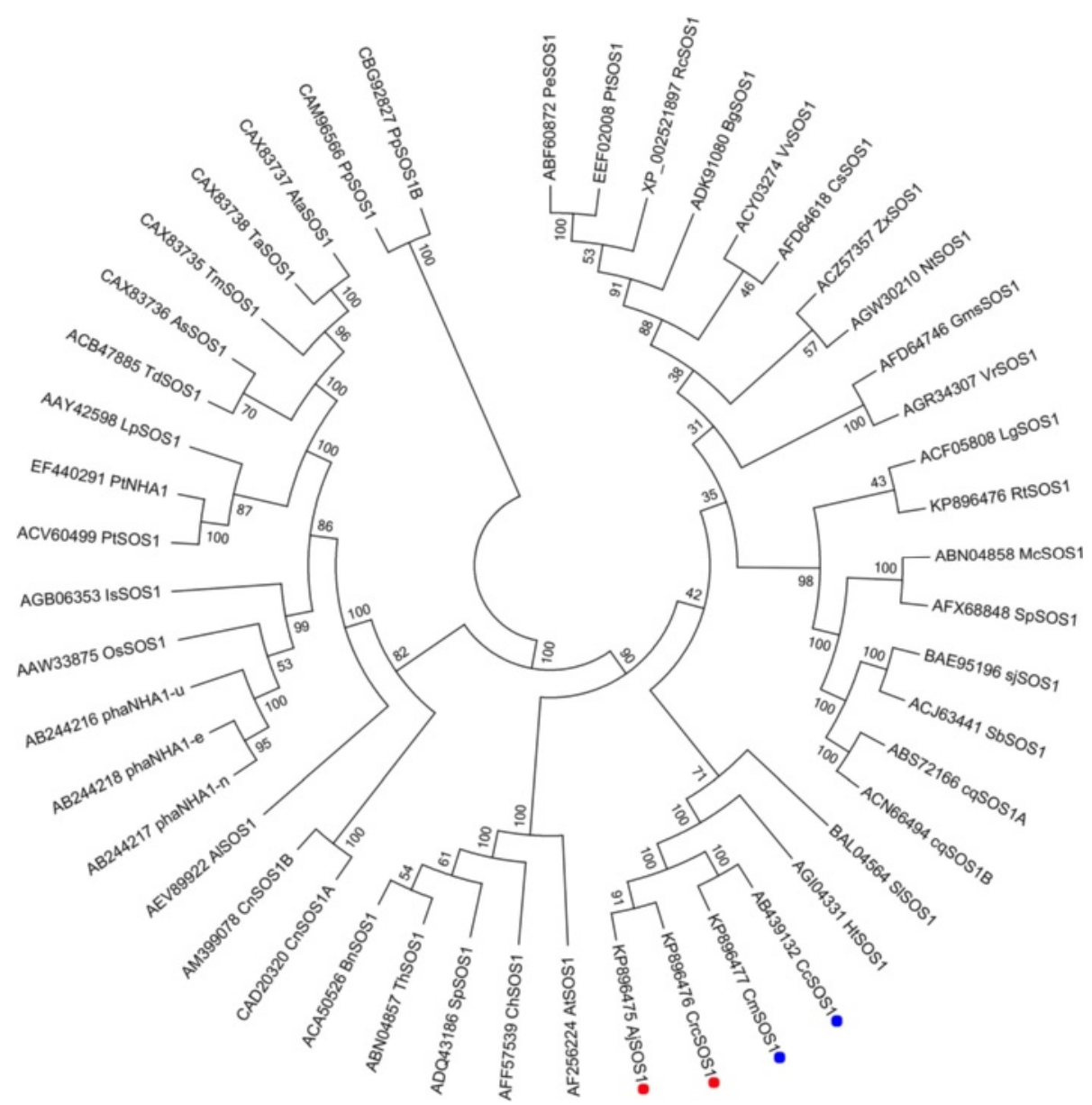

Fig. 4 Phylogeny of the SOS1 proteins. Artemisia japonic AjSOS (KP896475), Crossostephium chinense CrcSOS1 (KP896476), Chrysanthemum crissum CCSOS1 (AB439132), Chrysanthemum morifolium CmSOS1 (KP896477), Helianthus tuberosus HtSOS1 (AGI04331), Solanum lycopersicum SISOS1 (BAL04564), Arabidopsis thaliana AtSOS1 (AF256224), Cochlearia hollandica ChSOS1 (AFF57539), Schrenkiella parvula SpSOS1 (ADQ43186), Eutrema halophilum EhSOS1/ThSOS1 (ABN04857), Brassica napus BnSOS1 (ACA50526), Glycine max GmsSOS1 (AFD64746), Vigna radiata VrSOS1 (AGR34307), Zygophyllum xanthoxylum ZxSOS1 (ACZ57357), Cucumis sativus CsSOS1 (AFD64618), Vitis vinifera VvSOS1 (ACY03274), Populus euphratica PeSOS1 (ABF60872), Bruguiera gymnorhiza BgSOS1 (ADK91080), Limonium gmelinii LgSOS1 (ACF05808), Mesembryanthemum crystallinum McSOS1 (ABN04858), Sesuvium portulacastrum SpSOS1 (AFX68848), Suaeda japonica sjSOS1 (BAE95196), Salicornia brachiata SbSOS1 (ACJ63441), Chenopodium quinoa cqSOS1A (ABS72166); cqSOS1B (ACN66494), Cymodocea nodosa CnSOS1A (CAD20320); CnSOS1B (AM399078), Aeluropus littoralis AISOS1 (AEV89922), Phragmites australis PhaNHA1-n (AB244217); PhaNHA1-e (AB244218); PhaNHA1-u (AB244216), Oryza sativa OsSOS1 (AAW33875), Indosasa sinica IsSOS1 (AGB06353), Puccinellia tenuiflora PtSOS1 (ACV60499), Puccinellia tenuiflora PtNHA1 (EF440291), Lolium perenne LpSOS1 (AAY42598), Triticum durum TdSOS1 (ACB47885), Aegilops speltoides AsSOS1 (CAX83736), Triticum aestivum TaSOS1 (CAX83738), Aegilops tauschii AtaSOS1 (CAX83737), Triticum monococcum TmSOS1 (CAX83735), Physcomitrella patens PpSOS1 (CAM96566); PpSOS1B (CBG92827), Ricinus communis RCSOS1 (XP_002521897), Populus trichocarpa PtSOS1 (EEF02008), Nitraria tangutorum NtSOS1 (AGW30210), Reaumuria trigyna RtSOS1 (AGW30208). The sequences were aligned using Clustal $X$ and the phylogeny was constructed using the neighbor-joining method implemented in MEGA v5.0. The blue and red dots indicate the four SOS1s isolated here

tobacco [49]. The percentage survival of S1 and S2 plants was $33 \%$ and $36 \%$, respectively, whereas that of other transgenic plants was $49 \%-68 \%$ (Fig. 7b-c). Furthermore, each of two transgenic $A$. thaliana lines overexpressing four SOS1s were selected for further study. For example no expression of exogenous SOS1 was detected in $A$. thaliana wide type $g l 1$ but in these transgenic lines $\mathrm{M}-1, \mathrm{M}-2, \mathrm{~F}-1, \mathrm{~F}-2, \mathrm{D}-1, \mathrm{D}-2, \mathrm{~S}-1$ and $\mathrm{S}-2$, which showed a high expression level of SOS1 (Additional file 3: Figure S2a). On 1/2 MS medium containing 150 or $75 \mathrm{mM} \mathrm{NaCl}$, the seed germination rates, root length and fresh weight of transgenic $A$. thaliana wild type or sos1-1 lines were higher than those of the corresponding, and in the transgenic lines, the above index value in $\mathrm{gS}-1, \mathrm{gS}-2, \mathrm{sS}-1$ and sS-2 were also notably lower than that of other lines (Additional file 3: Figure S2 and Additional file 4: Figure S3). These results indicated that the differences between the SOS1 transcription level in the transgenic lines did not very important effect in their tolerance 

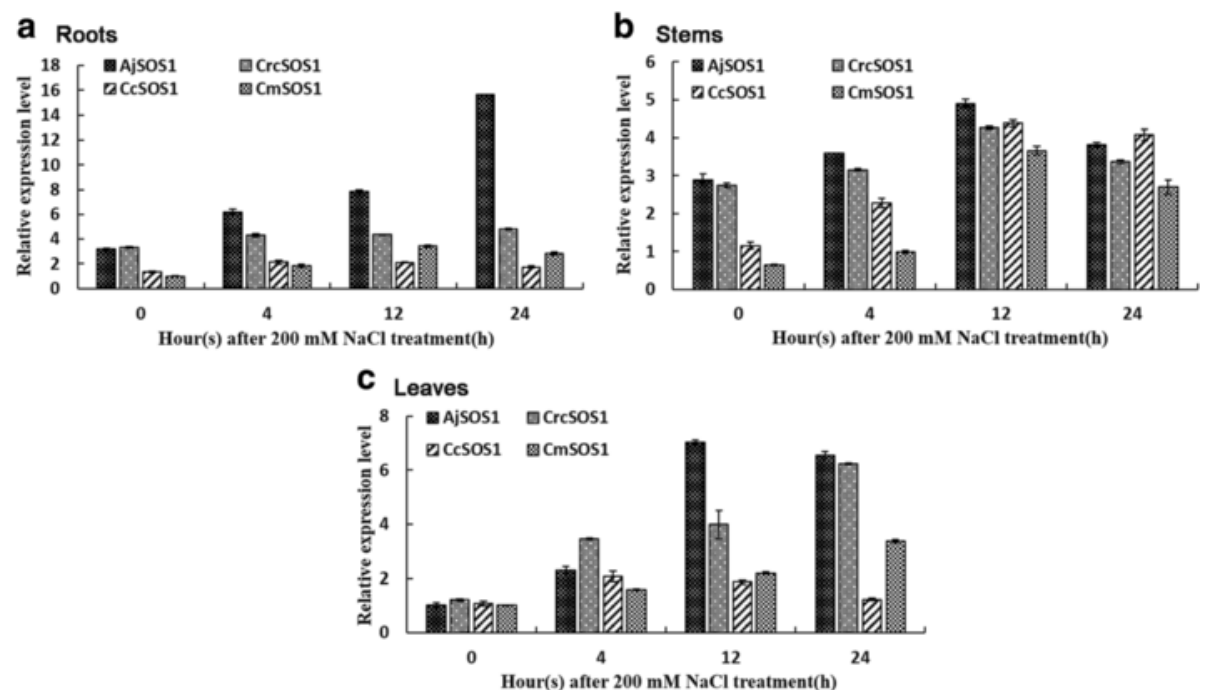

Fig. 5 qPCR based transcription profiling of the four SOS1 genes in response to salinity stress. Relative transcript abundances in the root (a), stem (b) and leaf (c). The relative expression in all tissues and time points was first compared to the reference genein each species and then calculated using the expression value at the initial time $(0 \mathrm{~h})$ in the root of CmSOS1. Data are presented as mean $\pm \mathrm{SE}(n=3)$. Actin was used as reference gene

to salinity, and over expression of four SOS1s enhanced the salinity tolerance of transgenic plants and the overexpressing plants of SOS1s from salt tolerant plants were more tolerant than SOS1s from salt sensitive plants.

\section{Site-Directed Mutagenesis functional analysis in yeast}

The site-directed mutagenesis applied to AjSOS1 produced a set of 18 residue polymorphisms and additional one site-directed mutagenesis applied to CcSOS1 (Additional file 2: Figure S4). The hypothesis was that mutations a critical residue in AjSOS1 or CCSOS1 would generate a loss of salinity tolerance, as assayed by the yeast complementation test. The mutated forms were introduced into ANT3, and the drop test was conducted on AP medium containing $70 \mathrm{mM} \mathrm{NaCl}$ and $1 \mathrm{mM} \mathrm{KCl}$. As depicted in Fig. 8, mutants G13E, T26S, F143I, V238L,

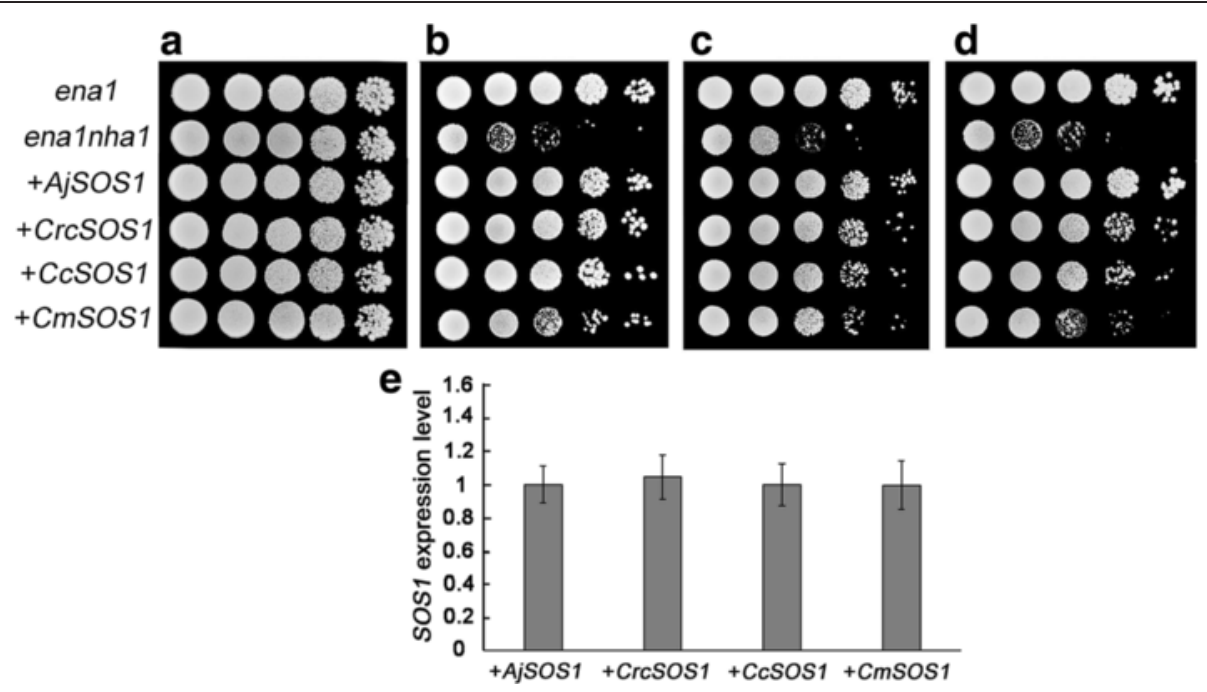

Fig. 6 Functional characterization of four SOS1s in the salinity sensitive yeast mutant ANT3 (ena1 nha1) and expression analysis of SOS1 gene in four SOS1s yeast transformants. ANT3 were transformed with plasmid containing four SOS1s (+AjSOS1, +CrCSOS1, +CcSOS1, +CmSOS1), G19 (ena1) and ANT3 (ena1 nha1) were transformed with the empty vector. G19 (ena1) cells were used as a positive control. Transformants were brought to a density $2 \times 10^{6}$ per $\mathrm{mL}$, of which $5 \mu \mathrm{L}$ (serially diluted) were spotted onto YPDA medium containing $0 \mathrm{mM} \mathrm{NaCl}$ (a) and AP medium containing 30 (b), 50 (c) and 70 (d) $\mathrm{mM} \mathrm{NaCl}$. Plates were incubated at $30{ }^{\circ} \mathrm{C}$ for 2-4 days. e qPCR analysis of SOS1 expression in four SOS1s yeast transformants. The actin gene was employed as an internal control 

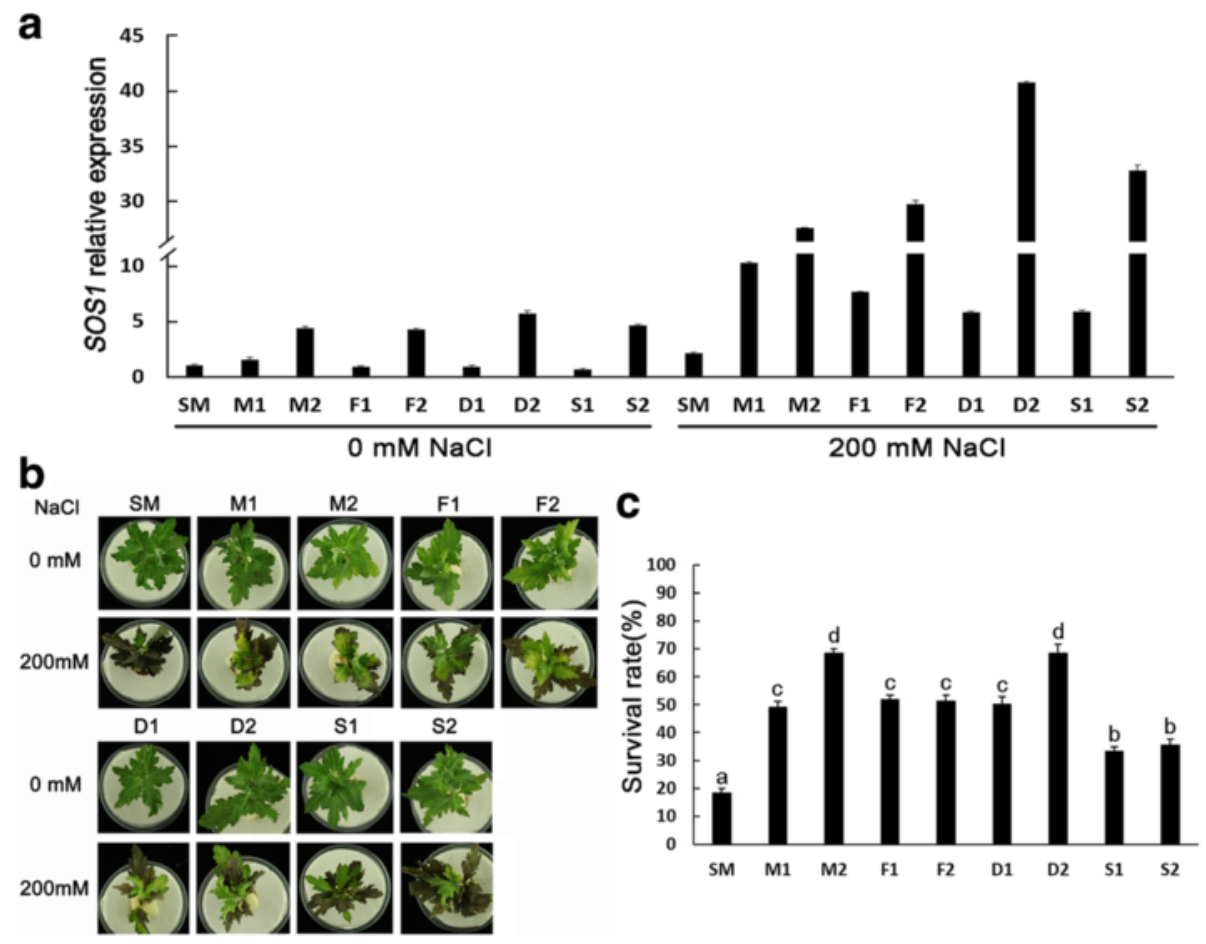

Fig. 7 Salinity tolerance of wide type 'Jinba' and transgenic chrysanthemum plants overexpressing four SOS1S. a Expression levels of SOS1 in wide type 'Jinba' and transgenic chrysanthemum lines overpressing four SOS15. SM, wide type 'Jinba' plant; M1 and M2, transgenic chrysanthemum lines of AjSOS1; F1 and F2, transgenic chrysanthemum lines of CrCSOS1; D1 and D2, transgenic chrysanthemum lines of CcSOS1; S1 and S2, transgenic chrysanthemum lines of CmSOS1. b Phenotypic response of saline hydroponics with $200 \mathrm{mM} \mathrm{NaCl}$ for 3 days. c Plant survival measured at 4 day in the presence of saline hydroponics with $200 \mathrm{mM} \mathrm{NaCl}$

Y463H, E512G, Y549H, S639L, A919T, YG927HS, G982V, A1027V, N1109K and G1127A failed to complement the growth defect of yeast cells, which suggested that these mutations couldn't mediate $\mathrm{Na}^{+}$efflux in yeast and may be important for transport activity and salt tolerance of AjSOS1. The other AjSOS1-mutants supported more cell growth than either empty vector transformed ANT3 cells or those transformed with CmSOS1, indicating that these mutants were null mutations.

\section{Discussion}

At the phenotypic level, $C$. chinense and A. japonica both appeared to tolerate salinity stress rather better than either C. crassum or C. morifolium (Fig. 1), this finding consistent with the division of 32 chrysanthemum-related taxa into four clusters based on their morphological response to the stress [32]. The primary effect of salinity stress is a disturbance of cellular ion homeostasis, followed by the ingress of toxic levels of $\mathrm{Na}^{+}$into the cytoplasm. Patterns of ion accumulation have been exploited with some success as a means of discriminating between tolerant and sensitive species/cultivars [50]. The present data showed that exposure to $200 \mathrm{mM} \mathrm{NaCl}$ induced a smaller increase in tissue $\mathrm{Na}^{+}$content and a less reduction in tissue $\mathrm{K}^{+}$ content and $\mathrm{K}^{+} / \mathrm{Na}^{+}$ratio in $C$. chinense and A. japonica than in C. crassum and C. morifolium (Fig. 2), consistent with the ranking based on the species' morphological response. The main conclusion was that the variation in salt tolerance displayed by the four species most likely reflected genetic variation for their ability to exclude the ingress of $\mathrm{Na}^{+}$, most probably thanks to have a more selective ion transport system. Similar conclusions have been drawn from the study of a range of other plant species [51-54]. $\mathrm{Na}^{+}$transporters are an important class of protein employed by $A$. thaliana to maintain ion homeostasis during an episode of salinity stress. The activity of AtSOS1 is central to the exclusion of $\mathrm{Na}^{+}$, as well as to its loading and retrieval into and out of the xylem [8]. The existence of an efficient SOS pathway would therefore make a major contribution to the superior salinity stress tolerance of $C$. chinense and $A$. japonica.

The SOS1 genes isolated from the four chrysanthemum and its related species all belong to the $A$. thaliana CPA1 (cation proton antiporter 1) family [6]. They all harbored three conserved functional domains Nhap, InhiBD and S2P (Fig. 3), a characteristic of SOS1 encoded proteins, and thought to be critical for their functionality [47]. In the absence of salinity stress, the abundance of SOS1 transcript in both the root and stem was higher in the more salinity tolerant $A$. japonica and 


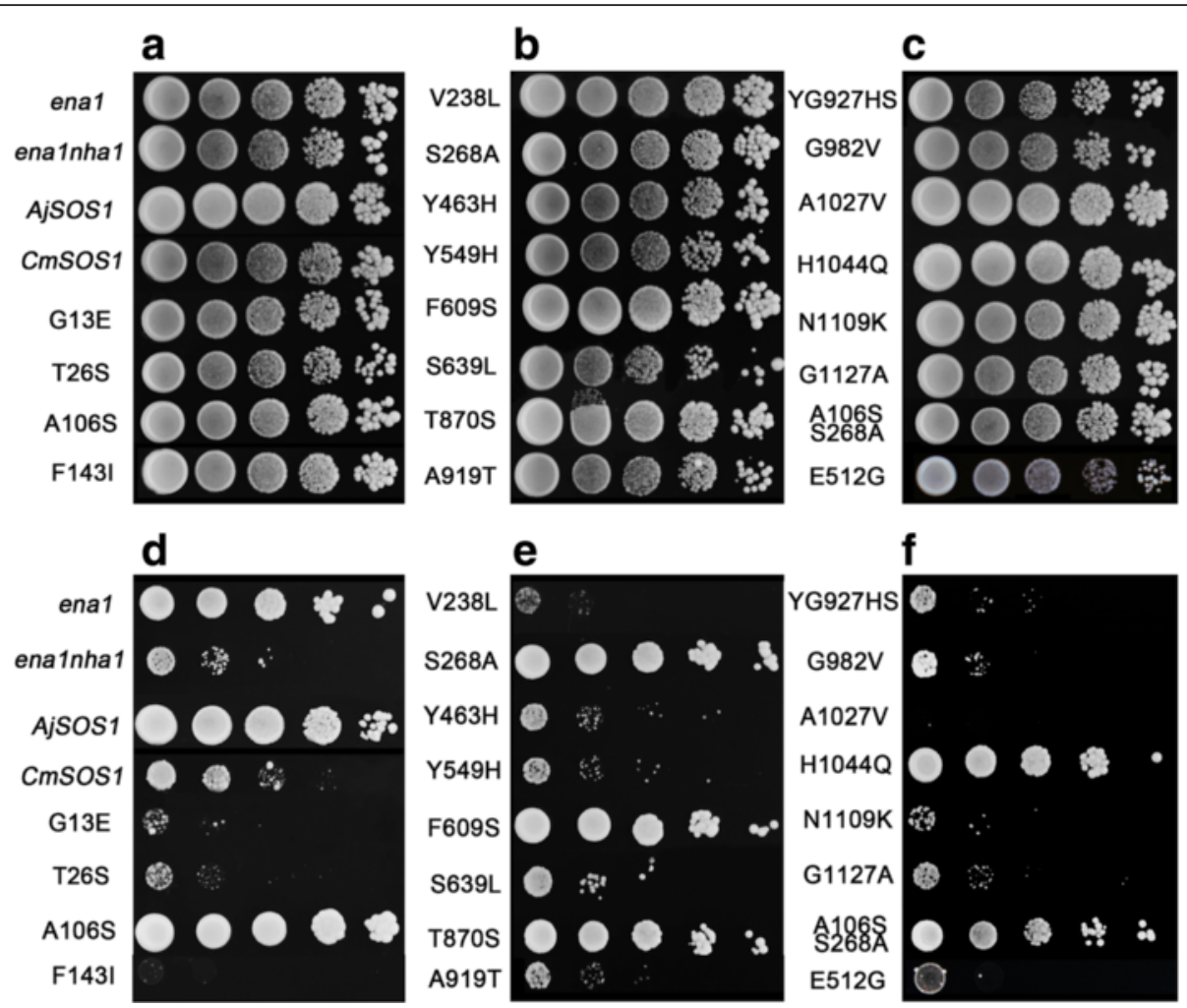

Fig. 8 The salinity tolerance of ANT3 cells expressing altered forms of AjSOS1. The yeast cells were cultured overnight and a $5 \mu \mathrm{L}$ aliquot (serially diluted) was spotted onto either a YPDA medium containing no $\mathrm{NaCl}(\mathbf{a}-\mathbf{c})$ or an AP medium containing $70 \mathrm{mM} \mathrm{NaCl}$ (d-e). Plates were incubated at $30^{\circ} \mathrm{C}$ for $2-4$ days

C. chinense than in either C. crassum or C. morifolium, whereas in the leaf, the SOS1 transcript abundance in the four species differed little. The SOS1 genes were all up-regulated throughout the plant when salinity stress was imposed, inducing much higher transcript levels in the root than in either the stem or the leaf (Fig. 5). Moreover, the transcripts of reference gene Actin in four tested plants after salt treatment were relatively constant (Additional file 5: Figure S1). The behavior of SOS1 genes in a range of glycophytes is quite similar [7, 10, $15,18,22,29,43,55]$, although in other species, salinity stress has been found to significantly up-regulate SOS1 in the leaf but not in root $[26,40,42,56]$. In the former case, the assumption is that the SOS1 protein acts to remove $\mathrm{Na}^{+}$from the root cell, while in the latter, they have been suggested to function as maintainers of a low cytosolic $\mathrm{Na}^{+}$concentration in the leaf to protect photosynthesis. Notably, the abundance of AjSOS1 and CrcSOS1 transcript in salinity-stressed plants was greater than that of CCSOS1 and CmSOS1, which concords with the differences in ion accumulation and salinity tolerance displayed by the four species. Similarly, in a contrast between the salinity tolerant Populus euphratica and the more sensitive Populus popularis, the former was seen to accumulate a higher transcript abundance of genes related to $\mathrm{Na}^{+} / \mathrm{H}^{+}$antiporter activity [57]. Likewise, in a comparison of four Brassica spp. accessions, the more salinity tolerant entries displayed the highest level of SOS1 transcription [53], while in bread wheat 'Kharchia 65', a cultivar known to be an efficient $\mathrm{Na}^{+}$exporter also showed high levels of SOS1 transcription [58]. Finally, in A. thaliana, the level of SOS1 transcription in the root has been shown to be inversely proportional to the accumulation of $\mathrm{Na}^{+}$in the plant [59]. Thus the evidence is very strong to support the notion that SOS1 proteins make an important contribution to salinity tolerance in the chrysanthemum species complex.

Heterologous expression in yeast has been exploited by a number of researchers aiming to functionally characterize plant SOS1 genes [10, 18, 20-22, 25, 60]. The ANT3-based system effectively discriminated between the efficacy of the chrysanthemum and its related species SOS1s in terms of their ability to counteract salinity stress. In particular, the assay showed that the AjSOS1 and CrCSOS1 products were able to compensate for the yeast host's lack of $\mathrm{Na}^{+}$-pumping ATPase ENA14 and plasma membrane $\mathrm{Na}^{+} / \mathrm{H}^{+}$antiporter NHA1 activity and the SOS1 expression levels of yeast transformants for four SOS1s were almost the same (Fig. 6). The 
implication is that these proteins mediate $\mathrm{Na}^{+}$efflux at the plasma membrane of yeast. Since AjSOS1, CrcSOS1 and $\operatorname{CCSOS1}$ were much more effective than CmSOS1, it seems probable that these proteins are key determinants of the contrasting ionic homeostasis and levels of salinity tolerance of the four species. Similar conclusions have been drawn by contrasting the effectiveness of an SOS1 gene isolated from the salinity tolerant species Thellungiella salsuginea with that of AtSOS1 [10], and that of the SOS1 genes from the two halophytes Eutrema salsugineum and Schrenkiella parvula [35]. Takahashi et al. (2009) have shown that yeast cells heterologously expressing a PhaNHA1 allele (PhaNHA1-n) isolated from a salinity tolerant reed plants grew better than those harboring an allele (PhaNHA1-u) isolated from a salinity sensitive accession [21].

Several researchs have been shown that transgenic plants over-expression SOS1 improved salt tolerance [18, 20, 27-31, 61]. In this study, we demonstrated that over expression of four SOS1s also enhanced the salinity tolerance of transgenic chrysanthemum and A. thaliana wild type or sos1-1, and the overexpressing plants of SOS1s from salt tolerant plants were more tolerant than that from salt sensitive plants (Fig. 7, Additional file 3: Figure S2 and Additional file 4: Figure S3). These results were consist with the above functional analysis in the yeast mutant. To understand the reason for the different activities at SOS1s, a multiple alignment of four SOS1s proteins was analyzed and found that the AjSOS1 and CrcSOS1 sequences differed from CcSOS1 and CmSOS1 with respect to eighteen residues, and additional one residues in which CmSOS1 encode amino acid relative to the same ones of the other three SOS1s, and of which six were located in the membrane-spanning region and the other thirteen in the hydrophilic tail (Fig. 3).

When site-directed mutagenesis was carried out, it was found that a number of the altered polypeptides had no deleterious effect on the ability to complement the lesion in the ANT3 cell line, showing that these residues were not determinants of the protein's functionality. However, some of the altered polypeptides (G13E, T26S, F143I, V238L, Y463H, E512G, Y549H, S639L, A919T, YG927HS, G982V, A1027V, N1109K and G1127A) did reduce the level of the yeast's salinity tolerance, implying that these were essential for endowing AjSOS1 with the capacity to compensate for the host's defective $\mathrm{Na}$ ${ }^{+}$-pumping ATPase and plasma membrane $\mathrm{Na}^{+} / \mathrm{H}^{+}$antiporter activity (Fig. 8). G13E and T26S lie at the $5^{\prime}$ end of TMD1, F143I and V238L in the TMD4 and TMD6 respectively, while the remaining sites map to the $\mathrm{C}$ terminal hydropholic tail. Transmembrane regions in plant NHAs are thought to be important for $\mathrm{Na}^{+}$and $\mathrm{H}^{+}$exchange. The presence of a cytoplasmic tail indicates that the transporter is probably regulated by an external signal: under either salinity or oxidative stress, the AtSOS1 cytoplasmic tail interacts with RCD1, a regulator of the oxidative stress response [62]. Therefore, it is possible that the differential activity of the four SOS1s reflects a dissimilar interaction between their cytoplasmic tail and a signaling protein such as RCD1. Some of the mutations to AjSOS1 are likely to have induced alterations to the protein's secondary structure (Additional file 6: Figure S5), thereby potentially affecting its regulation and functionality. In $A$. thaliana, the salinity sensitive mutations $\operatorname{sos} 1-3, \operatorname{sos} 1-8$, sos1-9 and sos1-12 each comprise a single residue substitution in AtSOS1 [7], while the substitution E1044V in the putative auto inhibitory domain of $E$. salsugineum ESSOS1 is necessary, but not sufficient to facilitate the growth of AXT3K (Dena1::HIS3::ena4, Dnha1::LEU2, $\Delta n h \times 1:: K a n M X 4)$ yeast cells cultured on a saline medium [35]. In Triticum durum, the mutation of TdSOS1 alleles S1126A and S1128A (DSPS mutated to DAPA) have been associated with a reduced phosphorylation ability by the A. thaliana SOS2 kinase T/DSOS2 $\Delta 308$, thereby preventing its activation of TdSOS1 [19]. Furthermore the alleles AtSOS1 S1136A and S1138A both interfere with phosphorylation by SOS2, while the G777D variant (sos1-8) is not activated by SOS2 [47]. Further investigations will be needed to provide much more evidences for contribution of the four SOS1s homologs in salt tolerance and to understand the basis of the observed variation in the activity of the AjSOS1 alleles.

\section{Conclusions}

In summary, in the four chrysanthemum and its related species, $C$. chinense, A. japonica and C. crassum were better tolerate than $C$. morifolium. They also had a superior capacity to prevent the accumulation of $\mathrm{Na}^{+}$and the reduction of $\mathrm{K}^{+}$in planta and their level of SOS1 transcription was higher. Moreover SOS1 sequence polymorphisms may be responsible for the higher efficacy of the AjSOS1 encoded protein. Taken together, AjSOS1, CrcSOS1 and CcSOS1 might be potential genes for enhancing salinity tolerance through transgenic strategies.

\section{Methods}

Plant materials, growing conditions and the assessment of salinity tolerance

Samples of C. chinense, A. japonica, C. crassum and C. morifolium were obtained from the Chrysanthemum Germplasm Resource Preserving Centre (Nanjing Agricultural University, China). Uniform cuttings were vegetatively propagated in sand. For experiments designed to estimate $\mathrm{Na}^{+}$and $\mathrm{K}^{+}$content under salinity stress, a set of rooted seedlings at the 6-10 leaf stage Iwas transplanted into a 1:1 mixture of garden soil and vermiculite, and the plants cultured under a $16 \mathrm{~h}$ photoperiod, a day/night temperature of $22{ }^{\circ} \mathrm{C} / 18{ }^{\circ} \mathrm{C}$ 
and a relative humidity of $68-75 \%$. The plants were irrigated with $200 \mathrm{mM} \mathrm{NaCl}$ every four days and photographed on day 10. Leaves, stems and roots were harvested separately on day 14 , baked at $80{ }^{\circ} \mathrm{C}$ for three days and weighed. A $0.1 \mathrm{~g}$ aliquot of each dry sample was digested in $2 \mathrm{~mL} 10 \mathrm{M} \mathrm{HNO}_{3}$, after which the solution were added to $10 \mathrm{~mL}$ with distilled water. $\mathrm{Na}^{+}$and $\mathrm{K}^{+}$contents were measured in this extract using an Optima 2100DV inductively coupled plasma optical emission spectrometer (Perkin Elmer, USA) [63]. Each sample was replicated three times. Means were compared using the Student's $t$ test implemented in SPSS v17.0 J software (SPSS Inc., Chicago, IL, USA).

\section{Isolation of SOS1 sequences}

RNA (ribonucleic acid) was extracted from roots of plants exposed to a hydroponic solution (half strength Hoagland's solution) containing $200 \mathrm{mM} \mathrm{NaCl}$ using the RNAiso reagent (TaKaRa Bio, Tokyo, Japan), following the manufacturer's protocol. A $1 \mu \mathrm{g}$ aliquot of this RNA was reverse transcribed via M-MLV reverse transcriptase (TaKaRa Bio), primed by Oligo $\mathrm{d}(\mathrm{T})_{18}$. The SOS1 coding regions were amplified from the first strand cDNA (complementary deoxyribonucleic acid) using fusion PCR/overlap PCR [64] and the primer pairs F1/R1 and F2/R2 (sequences given in Table 1). The full length cDNA sequences were deduced from $5^{\prime}$ and 3' RACE (rapid amplification of cDNA ends) amplicons [65], and then amplified from cDNA template using the primer pair Full-F/R (sequences given in Table 1). These amplicons were inserted into the pEASY-Blunt Zero Cloning vector (TransGen Biotech, Beijing, China) for sequence-based validation. Open reading frames (ORFs) was identified using the ORF finder program (www.ncbi.nlm.nih.gov/gorf/gorf.html). Hydrophobicity and

Table 1 Adaptor and PCR primer sequences

\begin{tabular}{|c|c|c|}
\hline Primer name & 5'-3' sequence & Usage \\
\hline F1 & ATGGGATCGGTGGCAAACAAC & overlap ORF fragment1 \\
\hline R1 & GCTTGTTTGCAGAAACTTGT & overlap ORF fragment1 \\
\hline F2 & ATTTCTAAATGGTGTGCAAGC & overlap ORF fragment2 \\
\hline R2 & TTAGGGAGCTCGGGGGAAAG & overlap ORF fragment2 \\
\hline Oligo d $(\mathrm{T})_{18}$ & TाTाताTाTाTाताTा & Reverse transcription \\
\hline AAP & GGCCACGCGTCGACTAGTACGGG\|GGG\|GGG\|G & $5^{\prime}-\mathrm{RACE}$ \\
\hline AUAP & GGCCACGCGTCGACTAGTAC & $5^{\prime}-$ RACE \\
\hline GSP5'-1 & CTCTAAGCAAATGTCTTG & $5^{\prime}-\mathrm{RACE}$ \\
\hline GSP5'-2 & TCCTCCTCCGCCCTTAG & $5^{\prime}-\mathrm{RACE}$ \\
\hline GSP5'-3 & GTTGGCACCGATCCCAT & $5^{\prime}-$ RACE \\
\hline Adaptor J-T & CTGATCTAGAGGTACCGGATCCTITITITITITITITIT & $3^{\prime}-\mathrm{RACE}$ \\
\hline Adaptor J-R & CTGATCTAGAGGTACCGGATCC & 3' -RACE \\
\hline GSP3'-1 & TCAGAAGGTTCTACGACAGTGAG & $3^{\prime}-\mathrm{RACE}$ \\
\hline GSP3'-2 & CCAGACCCAAATGATACTCGTGA & $3^{\prime}-$ RACE \\
\hline GSP3'-3 & TACACTATCTITCCCCCGAGCTC & $3^{\prime}-$ RACE \\
\hline Full-F & TGGTGGAGATGGGATCGGTGGCA & ORF amplifications \\
\hline Full-R & CTAGTAAATATATTATACAAGTC & ORF amplifications \\
\hline SOS1s-Sal-F & GCGTCGACATGGGATCGGTGGCAAACAACGTG & Functional complementation \\
\hline SOS1s-Not-R & TTGCGGCCGCGATTAGGGAGCTCGGGGGAAAG & Functional complementation \\
\hline Actin- $F$ & AGCTTGCATATGTTGCTCTTGA & qPCR \\
\hline Actin-R & TTACCGTAAAGGTCCTTCCTGA & qPCR \\
\hline DL-F & TGGAGCTGAGGATGAACA & qPCR \\
\hline DL-R & CTACCGTACTITCTATGAACAC & qPCR \\
\hline actin-F & GTGATGTCGATGTCCGTAA & qPCR \\
\hline actin-R & AGAAGCCAAGATAGAACCA & qPCR \\
\hline CmEF1a-F & TITGGTATCTGGTCCTGGAG & qPCR \\
\hline CmEF1a-R & CCATTCAAGCGACAGACTCA & qPCR \\
\hline AtAct2-F & TTCGTTTGCGTTTTAGTCCC & RT-PCR \\
\hline AtAct2-R & GGGAACAAAAGGAATAAAGAGGC & RT-PCR \\
\hline
\end{tabular}


putative transmembrane domain were predicted using the TMPRED program (www.ch.embnet.org/software/ TMPRED_form.html). Multiple peptide alignment and phylogenetic analysis were carried out by DNAman v5.2.2.0 software (Lynnon Biosoft, St Louis, Canada), Clustal $\mathrm{X}$ and MEGA v5.0, which utilized the NeighborJoining method.

\section{SOS1 transcription profiling}

Leaf, stem and root samples from four plants per species were collected at $0,4,12$ and $24 \mathrm{~h}$ following the addition of $200 \mathrm{mM} \mathrm{NaCl}$ to the hydroponic solution, snapfrozen in liquid nitrogen, and used as a source of cDNA to provide the template for a $\mathrm{qPCR}$ assay. The necessary RNA extraction and reverse transcription were performed as described above. The primer pair DL-F/R (sequences given in Table 1) were designed to amplify SOS1 fragment. The Actin gene (GenBank accession number AB205087) was used as the reference sequence. Each $20 \mu \mathrm{L}$ reaction contained $10 \mu \mathrm{L}$ SYBR Premix Ex $\mathrm{Taq}^{\mathrm{TM}}$ II (TaKaRa Bio), $10 \mathrm{ng}$ cDNA and $0.2 \mu \mathrm{M}$ of each primer. The amplification program comprised an initial denaturation $\left(95^{\circ} \mathrm{C} / 2 \mathrm{~min}\right)$, followed by 40 cycles of $95^{\circ}$ $\mathrm{C} / 15 \mathrm{~s}, 55{ }^{\circ} \mathrm{C} / 15 \mathrm{~s}$ and $72{ }^{\circ} \mathrm{C} / 20 \mathrm{~s}$. Relative transcript abundances were estimated using the $2^{-\Delta \Delta C t}$ method in compliance with MIQE guidelines [66, 67], and normalized against the transcript abundance at $0 \mathrm{~h}$ in the root of CmSOS1 at the respective time-point.

\section{Complementation by the four SOS1 genes in the yeast mutants ANT3}

The two bakers' yeast (Saccharomyces cerevisiae) mutant strains G19 (Dena1::HIS3::ena4) and ANT3 (Dena1::HIS3::ena4, $\triangle$ nha1::LEU2) were employed for performing a complementation assay. The former mutant lacks the $\mathrm{Na}^{+}$-pumping ATPase ENA1 to ENA4 while the latter,both the $\mathrm{Na}^{+}$-pumping ATPase and the plasma membrane $\mathrm{Na}^{+} / \mathrm{H}^{+}$antiporter NHA1 are defective $[8,68]$. First, the ORF of four SOS1s were amplified using Phusion High Fidelity DNA Polymerase (Thermo Scientific, USA) with the primer pair SOS1s-Sal-F/Not-R (sequences given in Table 1). Both the resulting amplicons and $\mathrm{pENTR}^{\mathrm{TM}} 1 \mathrm{~A}$ plasmid were digested with Sal I and Not I restriction sites and the corresponding bands were ligated to yield the entry vector $\mathrm{pENTR}^{\mathrm{TM}} 1 \mathrm{~A}-S O S 1 s$. Then the $\mathrm{pENTR}^{\mathrm{TM}} 1 \mathrm{~A}$ vector containing SOS1s were inserted into the yeast expression vector pAD426GPD [69] using LR Clonase II enzyme mix (Invitrogen, USA). The pAD426GPD-SOS1s constructs were validated by sequencing, then transformed into ANT3 cells, utilizing the Yeastmaker transformation system 2 (Clontech, Mountain View, CA, USA). The empty vector pAD426GPD was transformed into strain ANT3 and G19, which used as positive control. Transformants were selected by culturing on SD standard medium lacking uracil. The yeast cells' salinity tolerance phenotype was explored using a drop test in which a $5 \mu \mathrm{L}$ aliquot of a saturated yeast culture, along with a similar volume of a serial dilution, was spotted onto alkali cation-free AP plates containing $1 \mathrm{mM} \mathrm{KCl}$ and with $\mathrm{NaCl}$ as designated [68,70]. The plates were held at $30{ }^{\circ} \mathrm{C}$ for $2-4$ days before being photographed. Moreover, four SOS1s transformants were cultured overnight and extracted RNA by using a fungi RNA extraction kit (Huayueyang biotech, Beijing, China). The reverse transcription and $\mathrm{qPCR}$ were performed as described above. The gene specific primer pair were DL-F/R and the reference gene was actin (GenBank accession number AAA34391), primer sequences were given in Table 1.

\section{Generation of four SOS1s over-expressors and their re- sponse to salinity treatment}

To further analyze the function of the four SOS1s and confirm their importance in plant salt tolerance, the plasmid $\mathrm{pENTR}^{\mathrm{TM}} 1 \mathrm{~A}-S O S 1 s$ were subjected to the LR reaction to obtain expression vector pMDC32-SOS1s and introduced the constructs $2 \times 35 \mathrm{~S}::$ SOS1s into salt sensitive C. morifolium 'Jinba', $A$. thaliana (Columbia ecotype) wide type gl1 and mutant sos1-1 via Agrobacterium tumefaciens strain EHA105 mediated leaf disc and floral pollen dip method as described above [71]. RNA was isolated from control and $200 \mathrm{mM} \mathrm{NaCl}$ treated putative transgenic chrysanthemum and wide type (SM) plants, and processed for qPCR directed to SOS1 (using the primer pair DL-F/R) as described above. The primer pair $\mathrm{CmEF} 1 \alpha-\mathrm{F} / \mathrm{R}$ was used to amplify the reference gene $C m E F 1 \alpha$. Relative gene expression levels were also estimated using the $2^{-\Delta \Delta C t}$ method [66], and normalized against the expression level of SOS1 in wide type plants under control conditions. Twenty plants of each transgenic lines (M1, M2, F1, F2, D1, D2, S1 and S2) and SM plants with three replicates were exposed to either control and a liquid nutrient solution (half strength Hoagland's solution) supplemented with $200 \mathrm{mM} \mathrm{NaCl}$ conditions, photographed on day 3 and calculated the survival rate on day 4. In addition, putative Arabidopsis transformants were firstly screened on hygromycin medium and then identified by RT-PCR analysis, based on the primer pair DL-F/R. Transgenic lines were used to assess salinity tolerance on 1/2 MS (Murashige and Skoog) agar medium supplemented with $\mathrm{NaCl}$, as indicted for each case. Each experiment was performed three times and significant differences among treatments were identified by one-way analysis of variance and Tukey's multiple range test ( $p=$ 0.05). All statistical analyses were performed using SPSS v17.0 J software (SPSS Inc). 


\section{Site-directed mutagenesis and the efficacy of mutated forms of AjSOS1}

PCR-based site-directed mutagenesis was applied to the pENTR $^{\mathrm{TM}} 1 \mathrm{~A}-$ AjSOS1 construct using Pfusion High Fidelity DNA Polymerase (Thermo Scientific), based on the primers TB1F/R-TB18F/R according to manual of Quickchange ${ }^{\bullet}$ Site-Directed Mutagenesis Kit (Stratagene, La Jolla, CA, USA). In addition, we also produced another one mutations which was carried out on pENTR $^{\mathrm{TM}} 1 \mathrm{~A}-\mathrm{CcSOS} 1$ plasmid DNA and based on the primer TB19F/R. All the mutated primer sequences were given in Additional file 7: Table S1. Each $50 \mu \mathrm{L}$ reaction contained $5 \mu \mathrm{L} 10 \times$ reaction buffer, $1 \mu \mathrm{L} 10 \mathrm{mM}$ dNTP, $2 \mu \mathrm{L}$ of each primer $(10 \mu \mathrm{M} / \mathrm{L}), 1 \mu \mathrm{L}$ Pfu DNA Polymerase $(2.5 \mathrm{U} / \mu \mathrm{L})$ (Thermo Scientific), $2 \mu \mathrm{L}$ plasmid DNA $(5 \mathrm{ng} / \mu \mathrm{l})$ and $37 \mu \mathrm{L} d \mathrm{dH}_{2} \mathrm{O}$. The reactions were initially denatured $\left(95{ }^{\circ} \mathrm{C} / 30 \mathrm{~s}\right)$, then subjected to 16 cycles of $95{ }^{\circ} \mathrm{C} / 30 \mathrm{~s}, 55^{\circ} \mathrm{C} / 60 \mathrm{~s}$ and $72{ }^{\circ} \mathrm{C} / 7 \mathrm{~min}$. The resulting amplicons were digested with $D p n$ I and then inserted into E. coli $\mathrm{DH} 5 \alpha$ competent cells. All plasmid constructs were sequenced to ensure that no unexpected mutations or cloning errors had occurred. The mutated constructs were then recombined into pAD426GPD and transformed in mutant ANT3 to assay the cells' salinity tolerance phenotype, as described above.

\section{Plant line abbreviations}

M1 and M2 (Transgenic chrysanthemum lines of AjSOS1), F1 and F2 (Transgenic chrysanthemum lines of CrcSOS1), D1 and D2 (Transgenic chrysanthemum lines of CcSOS1), S1 and S2 (Transgenic chrysanthemum lines of CmSOS1), SM (Wide type 'Jinba' plant).

gM-1 and gM-2 (Transgenic lines of AjSOS1 in A. thaliana wide type gl1), gF-1 and gF-2 (Transgenic lines of CrcSOS1 in A. thaliana wide type gl1), gD-1 and gD-2 (Transgenic lines of CcSOS1 in A. thaliana wide type gl1), gS1 and gS2 (Transgenic lines of CmSOS1 in A. thaliana wide type gl1).

sM-1 and sM-2 (Transgenic lines of AjSOS1 in A. thaliana mutant sos1-1), sF-1 and sF-2 (Transgenic lines of CrcSOS1 in A. thaliana mutant sos 1-1), sD-1 and sD2 (Transgenic lines of CCSOS1 in A. thaliana mutant sos1-1), sS1 and sS2 (Transgenic lines of CmSOS1 in A. thaliana mutant sos 1-1).

\section{Ethics (and consent to participate) \\ Not applicable.}

\section{Consent to publish}

Not applicable.

\section{Availability of data and materials}

The data sets supporting the results of this article are included within the article and its additional files.

\section{Additional files}

Additional file 1: Table S2. Summary details of the four SOS1 sequences isolated from chrysanthemum and its close relatives. (DOCX $14 \mathrm{~kb})$

Additional file 2: Figure S4. The site-directed amino acid in AjSOS1 secondary structure as predicted by TMPRED. (TIF 574 kb)

Additional file 3: Figure S2. Salt tolerance phenotypes of transgenic A. thaliana wide type gl1 lines. (a) RT-PCR analysis of SOS1 in transgenic lines and wide type gl1. (b) Seeds of wide type gl1 and the four SOS1stransgenic lines (gM-1, gM-2, gF-1, gF-2, gD-1, gD-2, gS-1 and gS-2) were germinated directly on 1/2 MS medium and on 1/2 MS mediumsupplemented with $150 \mathrm{mM} \mathrm{NaCl}$, and then grown for 7 days. (c) Six-day-old seedlings of gl1 and eight transgenic lines (gM-1, gM-2, gF-1, gF-2, gD-1, gD-2, gS-1 and gS-2) were transferred to $1 / 2$ MS medium containing $150 \mathrm{mM} \mathrm{NaCl}$. The pictures were taken sfter 14 days of treatment. seedling primary root lenth (d) and fresh weight (e) were measured at day 14 after transfer. Error bars represent SD $(n=15)$. (TIF $7669 \mathrm{~kb})$

Additional file 4: Figure S3. Functional complementation of Arabidopsis mutant sos1-1 by four SOS1s. (a) Germination of sos1-1 and eight transgenic Arabidopsis mutant sos 1-1 lines (sM-1, sM-2, sF-1, sF-2, sD-1, sD-2, sS-1 and sS-2) after 7 days sown on 1/2 MS and 1/2 MS with $75 \mathrm{mM} \mathrm{NaCl}$. (b) Mutant sos1-1 and four SOS1s transgenic seedlings grown on 1/2 MS medium for six days and then transferred to 1/2 MS medium containing $75 \mathrm{mM} \mathrm{NaCl}$ and imaged after 7 days of salt treatment and the root elongation (c) and fresh weight of each of above mentioned lines were measured. Error bars represent SD $(n=15)$. (TIF 1979 kb)

Additional file 5: Figure S1. Amplification curves (a) and melting curve analysis (b) of reference gene Actin in four tested plants after salt treatment. (TIF $2714 \mathrm{~kb}$ )

Additional file 6: Figure S5. The predicted secondary structure of AjSOS1 prior to and after site-directed mutagenesis by DNAStar software. (TIF 2480 kb)

Additional file 7: Table S1. Oligonucleotide sequences used for the site-directed mutagenesis. (DOCX $15 \mathrm{~kb}$ )

\section{Abbreviations}

CDNA: complementary deoxyribonucleic acid; MS: Murashige and Skoog; ORF: open reading frames; qPCR: quantitative real-time polymerase chain reaction; RACE: rapid amplification of cDNA ends; RNA: ribonucleic acid; WT: wide type.

\section{Competing interests}

The authors declare that they have no competing interests.

\section{Authors' contributions}

JG and PC carried out the physiological assays; JG and JS carried out the molecular genetic studies; JG and CL performed yeast complementation expriments; JG and LR analysed the data. JG drafted the manuscript; SC and $J J$ edited and revised the manuscript; FC and JJ conceived the study and designed the experiments. All authors read and approved the final manuscript.

\section{Acknowledgments}

We thank Dr Huazhong Shi (Department of Chemistry and Biochemistry, Texas Tech University, USA) for the gift of yeast strains G19 and ANT3.

\section{Funding}

This research was supported by the Chinese Government "National Natural Science Foundation" (grant number 31171987), the Chinese Ministry of Education "Program for New Century Excellent Talents in University" (NCET12-0890), "Programs of Innovation and Entrepreneurship Talents" of Jiangsu Province, and the Priority Academic "Program Development of Jiangsu Higher Education Institutions".

Received: 1 September 2015 Accepted: 13 April 2016 Published online: 21 April 2016 


\section{References}

1. Munns R, Tester M. Mechanisms of salinity tolerance. Annual Review of Plant Biology. 2008;59:651-81.

2. Tester $\mathrm{M}$, Davenport $\mathrm{R} . \mathrm{Na}^{+}$tolerance and $\mathrm{Na}^{+}$transport in higher plants. Annals of Botany. 2003;91(5):503-27.

3. Apse MP, Blumwald E. $\mathrm{Na}^{+}$transport in plants. FEBS Letters. 2007;581(12): 2247-54.

4. Niu X, Bressan RA, Hasegawa PM, et al. lon homeostasis in $\mathrm{NaCl}$ stress environments. Plant Physiology. 1995;109(3):735-42.

5. Rajendran K, Tester M, Roy SJ. Quantifying the three main components of salinity tolerance in cereals. Plant Cell and Environment. 2009;32(3):237-49.

6. Pardo JM, Cubero B, Leidi EO, Quintero FJ. Alkali cation exchangers: roles in cellular homeostasis and stress tolerance. Journal of Experimental Botany. 2006;57(5):1181-99.

7. Shi H, Ishitani M, Kim C, Zhu JK. The Arabidopsis thaliana salt tolerance gene SOS1 encodes a putative $\mathrm{Na}^{+} / \mathrm{H}^{+}$antiporter. Proceedings of the National Academy of Sciences. 2000;97(12):6896.

8. Shi H, Quintero FJ, Pardo JM, Zhu JK. The putative plasma membrane $\mathrm{Na}^{+} / \mathrm{H}$ ${ }^{+}$antiporter SOS1 controls long-distance $\mathrm{Na}^{+}$transport in plants. The Plant Cell. 2002;14(2):465-77.

9. Olias R, Eljakaoui Z, Li J, et al. The plasma membrane $\mathrm{Na}^{+} / \mathrm{H}^{+}$antiporter SOS1 is essential for salt tolerance in tomato and affects the partitioning of $\mathrm{Na}^{+}$between plant organs. Plant, Cell and Environment. 2009;32(7):904-16.

10. Oh DH, Leidi $E$, Zhang $Q$, et al. Loss of halophytism by interference with SOS1 expression. Plant Physiology. 2009;151(1):210-22.

11. Wu SJ, Ding L, Zhu JK. SOS1, a genetic locus essential for salt tolerance and potassium acquisition. The Plant Cell Online. 1996:8(4):617-27.

12. Zhu JK, Liu J, Xiong L. Genetic analysis of salt tolerance in Arabidopsis: evidence for a critical role of potassium nutrition. The Plant Cell Online. 1998;10(7):1181-91.

13. Shabala $L$, Cuin TA, Newman IA, Shabala S. Salinity-induced ion flux patterns from the excised roots of Arabidopsis sos mutants. Planta. 2005;222(6):1041-50.

14. Qi Z, Spalding EP. Protection of plasma membrane $\mathrm{K}^{+}$transport by the salt overly sensitive1 $\mathrm{Na}^{+}-\mathrm{H}^{+}$antiporter during salinity stress. Plant Physiology. 2004;136(1):2548-55.

15. Ma Q, Li YX, Yuan HJ, Hu J, et al. ZxSOS1 is essential for long-distance transport and spatial distribution of $\mathrm{Na}^{+}$and $\mathrm{K}^{+}$in the xerophyte Zygophyllum xanthoxylum. Plant and Soil. 2014;374(1-2):661-76.

16. Zhu JK. Regulation of ion homeostasis under salt stress. Current Opinion in Plant Biology. 2003;6(5):441-5.

17. Zhang JL, Shi H. Physiological and molecular mechanisms of plant salt tolerance. Photosynthesis Research. 2013;155(1):1-22.

18. Martínez-Atienza J, Jiang X, Garciadeblas B, Mendoza I, Zhu JK, Pardo JM, Quintero FJ. Conservation of the salt overly sensitive pathway in rice. Plant Physiology. 2007;143(2):1001-12.

19. Feki K, Quintero FJ, Pardo JM, Masmoudi K. Regulation of durum wheat Na ${ }^{+} / \mathrm{H}^{+}$exchanger TdSOS1 by phosphorylation. Plant Molecular Biology. 2011; 76(6):545-56.

20. Tang RJ, Liu H, Bao Y, Lv QD, Yang L, Zhang HX. The woody plant poplar has a functionally conserved salt overly sensitive pathway in response to salinity stress. Plant Molecular Biology. 2010;74(4-5):367-80.

21. Takahashi R, Liu S, Takano T. Isolation and characterization of plasma membrane $\mathrm{Na}^{+} / \mathrm{H}^{+}$antiporter genes from salt-sensitive and salt-tolerant reed plants. Journal of Plant Physiology. 2009;166(3):301-9.

22. $\mathrm{Xu} \mathrm{H}$, Jiang $\mathrm{X}$, Zhan $\mathrm{K}$, et al. Functional characterization of a wheat plasma membrane $\mathrm{Na}^{+} / \mathrm{H}^{+}$antiporter in yeast. Archives of Biochemistry and Biophysics. 2008:473(1):8-15.

23. Song A, Lu J, Jiang J, Chen S, Guan Z, Fang W, Chen F. Isolation and characterisation of Chrysanthemum crassum SOS1, encoding a putative plasma membrane $\mathrm{Na}^{+} / \mathrm{H}^{+}$antiporter. Plant Biology. 2012;14(5):706-13.

24. Fraile-Escanciano A, Kamisugi Y, Cuming AC, Rodriguez-Navarro A, Benito B. The SOS1 transporter of Physcomitrella patens mediates sodium efflux in planta. The New Phytologist. 2010;188(3):750-61.

25. Garciadeblás B, Haro R, Benito B. Cloning of two SOS1 transporters from the seagrass Cymodocea nodosa. SOS1 transporters from Cymodocea and Arabidopsis mediate potassium uptake in bacteria. Plant Molecular Biology. 2007:63(4):479-90

26. Wu Y, Ding N, Zhao X, Zhao M, Chang Z, Liu J, Zhang L. Molecular characterization of PeSOS1: the putative $\mathrm{Na}^{+} / \mathrm{H}^{+}$antiporter of Populus euphratica. Plant Molecular Biology. 2007;65(1):1-11.
27. Wang X, Yang R, Wang B, Liu G, Yang C, Cheng Y. Functional characterization of a plasma membrane $\mathrm{Na}^{+} / \mathrm{H}^{+}$antiporter from alkali grass (Puccinellia tenuiflora). Molecular Biology Reports. 2011;38(7):4813-22.

28. Yang Q, Chen ZZ, Zhou XF, et al. Overexpression of SOS (Salt Overly Sensitive) genes increases salt tolerance in transgenic Arabidopsis. Molecular Plant. 2009:2(1):22-31.

29. Yadav NS, Shukla PS, Jha A, et al. The SbSOS1 gene from the extreme halophyte Salicornia brachiata enhances $\mathrm{Na}^{+}$loading in xylem and confers salt tolerance in transgenic tobacco. BMC Plant Biology. 2012;12(1):188.

30. Yue $Y$, Zhang M, Zhang J, Duan L, Li Z. SOS1 gene overexpression increased salt tolerance in transgenic tobacco by maintaining a higher $\mathrm{K}^{+} / \mathrm{Na}^{+}$ratio. Journal of Plant Physiology. 2012;169(3):255-61.

31. An J, Song A, Guan Z, et al. The over-expression of Chrysanthemum crassum CCSOS1 improves the salinity tolerance of chrysanthemum. Molecular Biology Reports. 2014:41(6):4155-62.

32. Guan Z, Chen S, Chen F, et al. Salt tolerance screening of 32 taxa from Chrysanthemum and its relative genera. Scientia Agricultura Sinica. 2010; 43(19):4063-71.

33. Li Q, Tang Z, Hu Y, Yu L, Liu Z, Xu G. Functional analyses of a putative plasma membrane $\mathrm{Na}^{+} / \mathrm{H}^{+}$antiporter gene isolated from salt tolerant Helianthus tuberosus. Molecular Biology Reports. 2014:41(8):5097-108.

34. Nawaz I, lqbal M, Hakvoort HWJ, et al. Expression levels and promoter activities of candidate salt tolerance genes in halophytic and glycophytic Brassicaceae. Environmental and Experimental Botany. 2014;99:59-66.

35. Jarvis DE, Ryu CH, Beilstein MA, Schumaker KS. Distinct roles for SOS1 in the convergent evolution of salt tolerance in Eutrema salsugineum and Schrenkiella parvula. Molecular Biology and Evolution. 2014;31(8):2094-107.

36. Oh DH, Gong Q, Ulanov A, et al. Sodium stress in the halophyte Thellungiella halophila and transcriptional changes in a thsos 1-RNA interference line. Journal of Integrative Plant Biology. 2007;49(10):1484-96.

37. Nie W, Xu L, Yu B. A putative soybean GmsSOS1 confers enhanced salt tolerance to transgenic Arabidopsis sos 1-1 mutant. Protoplasma. 2015;252(1):127-34.

38. Wang S, Li Z, Rui R, Fan GS, Lin KW. Cloning and characterization of a plasma membrane $\mathrm{Na}^{+} / \mathrm{H}^{+}$antiporter gene from Cucumis sativus. Russian Journal of Plant Physiology. 2013;60(3):330-6.

39. Jaillon O, Aury JM, Noel B, et al. The grapevine genome sequence suggests ancestral hexaploidization in major angiosperm phyla. Nature. 2007; 449(7161):463-7.

40. Cosentino C, Fischer SE, Bertl A, Thiel G, Homann U. Na ${ }^{+} / \mathrm{H}^{+}$antiporters are differentially regulated in response to $\mathrm{NaCl}$ stress in leaves and roots of Mesembryanthemum crystallinum. New Phytologist. 2010;186(3):669-80.

41. Zhou Y, Yin X, Duan R, Hao G, Guo J, Jiang X. SpAHA1 and SpSOS1 coordinate in transgenic yeast to improve salt tolerance. PLoS One. 2015; 10(9):e0137447.

42. Maughan PJ, Turner TB, Coleman CE, et al. Characterization of Salt Overly Sensitive 1 (SOS1) gene homoeologs in quinoa (Chenopodium quinoa Willd.). Genome. 2009:52(7):647-57.

43. Guo Q, Wang P, Ma Q, Zhang JL, Bao AK, Wang SM. Selective transport capacity for $\mathrm{K}^{+}$over $\mathrm{Na}^{+}$is linked to the expression levels of PtSOS1 in halophyte Puccinellia tenuiflora. Functional Plant Biology. 2012;39(12):1047-57.

44. Wang $H$, Zhang $P$, Liu D, et al. Isolation and characterization of a plasma membrane $\mathrm{Na}^{+} / \mathrm{H}^{+}$antiporter gene TaSOS1 from wheat. 2008.

45. Tuskan GA, DiFazio S, Jansson S, et al. The genome of black cottonwood, Populus trichocarpa (Torr. \& Gray). Science. 2006;313(5793):1596-604.

46. Dang $Z$, Zheng $L$, Feng $Z$, et al. Cloning and sequence analysis of the plasma membrane $\mathrm{Na}^{+} / \mathrm{H}^{+}$antiporter CDNA in Recretohalophyte Reaumuria trigyna Maxim. Acta Agriculturae Boreali-Sinica. 2013;28(3):1-6.

47. Quintero FJ, Martínez-Atienza J, Villalta I, et al. Activation of the plasma membrane $\mathrm{Na} / \mathrm{H}$ antiporter Salt-Overly-Sensitive 1 (SOS1) by phosphorylation of an auto-inhibitory C-terminal domain. Proceedings of the National Academy of Sciences. 2011;108(6):2611-6.

48. Kong X, Pan J, Zhang M, et al. ZmMKK4, a novel group C mitogen-activated protein kinase kinase in maize (Zea mays), confers salt and cold tolerance in transgenic Arabidopsis. Plant, Cell and Environment. 2011;34(8):1291-303.

49. Wang S, Uddin MI, Tanaka K, et al. Maintenance of chloroplast structure and function by overexpression of the rice MONOGALACTOSYLDIACYLGLYCEROL SYNTHASE gene leads to enhanced salt tolerance in tobacco. Plant Physiology. 2014;165(3):1144-55

50. Shannon MC, Grieve CM. Tolerance of vegetable crops to salinity. Scientia Horticulturae. 1999:78(1):5-38. 
51. Chen S, Li J, Wang S, Fritz E, Hüttermann A, Altman A. Effects of $\mathrm{NaCl}$ on shoot growth, transpiration, ion compartmentation, and transport in regenerated plants of Populus euphratica and Populus tomentosa. Canadian Journal of Forest Research. 2003:33(6):967-75.

52. Chen S, Li J, Wang S, Hüttermann A, Altman A. Salt, nutrient uptake and transport, and ABA of Populus euphratica; a hybrid in response to increasing soil NaCl. Trees. 2001;15(3):186-94.

53. Chakraborty K, Sairam RK, Bhattacharya RC. Differential expression of salt overly sensitive pathway genes determines salinity stress tolerance in Brassica genotypes. Plant Physiology and Biochemistry. 2012;51:90-101.

54. Kumar G, Purty RS, Sharma MP, Singla-Pareek SL, Pareek A. Physiological responses among Brassica species under salinity stress show strong correlation with transcript abundance for SOS pathway-related genes. Journal of Plant Physiology. 2009;166(5):507-20.

55. Kant S, Kant P, Raveh E, Barak S. Evidence that differential gene expression between the halophyte, Thellungiella halophila, and Arabidopsis thaliana is responsible for higher levels of the compatible osmolyte proline and tight control of $\mathrm{Na}^{+}$uptake in T. halophila. Plant, Cell and Environment. 2006; 29(7):1220-34.

56. Ruiz-Carrasco K, Antognoni F, Coulibaly AK, et al. Variation in salinity tolerance of four lowland genotypes of quinoa (Chenopodium quinoa Willd.) as assessed by growth, physiological traits, and sodium transporter gene expression. Plant Physiology and Biochemistry. 2011;49(11):1333-41.

57. Ding M, Hou P, Shen $X$, et al. Salt-induced expression of genes related to $\mathrm{Na}^{+} / \mathrm{K}^{+}$and ROS homeostasis in leaves of salt-resistant and salt-sensitive poplar species. Plant Molecular Biology. 2010;73(3):251-69.

58. Cuin TA, Bose J, Stefano G, Jha D, Tester M, Mancuso S, Shabala S. Assessing the role of root plasma membrane and tonoplast $\mathrm{Na}^{+} / \mathrm{H}^{+}$exchangers in salinity tolerance in wheat: in planta quantification methods. Plant Cell and Environment. 2011;34(6):947-61.

59. Jha D, Shirley $N$, Tester $M$, et al. Variation in salinity tolerance and shoot sodium accumulation in Arabidopsis ecotypes linked to differences in the natural expression levels of transporters involved in sodium transport. Plant, Cell and Environment. 2010;33(5):793-804

60. Quintero FJ, Ohta M, Shi H, Zhu JK, Pardo JM. Reconstitution in yeast of the Arabidopsis SOS signaling pathway for $\mathrm{Na}^{+}$homeostasis. Proceedings of the National Academy of Sciences. 2002;99(13):9061-6.

61. Shi H, Lee B, Wu SJ, Zhu JK. Overexpression of a plasma membrane $\mathrm{Na}^{+} / \mathrm{H}^{+}$ antiporter gene improves salt tolerance in Arabidopsis thaliana. Nature Biotechnology. 2002;21(1):81-5.

62. Katiyar-Agarwal S, Zhu J, Kim K, Agarwal M, Fu X, Huang A, Zhu JK. The plasma membrane $\mathrm{Na}^{+} / \mathrm{H}^{+}$antiporter SOS1 interacts with RCD1 and functions in oxidative stress tolerance in Arabidopsis. Proceedings of the National Academy of Sciences. 2006;103(49):18816-21.

63. Gao X, Ren Z, Zhao Y, Zhang H. Overexpression of SOD2 increases salt tolerance of Arabidopsis. Plant Physiology. 2003;133(4):1873-81.

64. Razzaque S, Elias SM, Biswas S, Haque T, Seraj Zl. Cloning of the plasma membrane sodium/hydrogen antiporter SOS1 for its over expression in rice. Plant Tissue Culture and Biotechnology. 2014;23(2):263-73.

65. Liu P, Chen S, Song A, et al. A putative high affinity phosphate transporter, CmPT1, enhances tolerance to Pi deficiency of chrysanthemum. BMC Plant Biology. 2014;14(1):18.

66. Livak KJ, Schmittgen TD. Analysis of relative gene expression data using real-time quantitative PCR and the $2_{T}^{-\Delta \Delta C}$ Method. Methods. 2001;25(4):402-8.

67. Bustin SA, Benes V, Garson JA, et al. The MIQE guidelines: minimum information for publication of quantitative real-time PCR experiments. Clinical Chemistry. 2009;55(4):611-22.

68. Quintero FJ, Blatt MR, Pardo JM. Functional conservation between yeast and plant endosomal $\mathrm{Na}^{+} / \mathrm{H}^{+}$antiporters. FEBS Letters. 2000;471(2):224-8.

69. Alberti S, Gitler AD, Lindquist S. A suite of Gateway ${ }^{\circledast}$ cloning vectors for high throughput genetic analysis in Saccharomyces cerevisiae. Yeast. 2007; 24(10):913-9.

70. Rodríguez-Navarro A, Ramos J. Dual system for potassium transport in Saccharomyces cerevisiae. Journal of Bacteriology. 1984;159(3):940-5.

71. Li P, Song A, Gao C, et al. Chrysanthemum WRKY gene CmWRKY 17 negatively regulates salt stress tolerance in transgenic chrysanthemum and Arabidopsis plants. Plant Cell Reports. 2015;34(8):1365-78.

\section{Submit your next manuscript to BioMed Central and we will help you at every step:}

- We accept pre-submission inquiries

- Our selector tool helps you to find the most relevant journal

- We provide round the clock customer support

- Convenient online submission

- Thorough peer review

- Inclusion in PubMed and all major indexing services

- Maximum visibility for your research

Submit your manuscript at www.biomedcentral.com/submit
( ) BioMed Central 